\title{
Toward atomic force microscopy and mass spectrometry to visualize and identify lipid rafts in plasmodesmata
}

\author{
Pamela A. Naulin, Natalia A. Alveal and Nelson P. Barrera* \\ Department of Physiology, Faculty of Biological Sciences, Pontificia Universidad Católica de Chile, Santiago, Chile
}

\section{Edited by:}

Emmanuelle Bayer, Centre National de la Recherche Scientifique, France

Reviewed by:

Scott D. Russell, University of

Oklahoma, USA

Laetitia Fouillen, Laboratoire de

Biogènese Membranaire, France

*Correspondence:

Nelson P. Barrera, Department of

Physiology, Faculty of Biological

Sciences, Pontificia Universidad

Católica de Chile, Alameda 340,

Santiago 8331150, Chile

e-mail:nbarrera@bio.puc.cl
Plant cell-to-cell communication is mediated by nanopores called plasmodesmata (PDs) which are complex structures comprising plasma membrane (PM), highly packed endoplasmic reticulum and numerous membrane proteins. Although recent advances on proteomics have led to insights into mechanisms of transport, there is still an inadequate characterization of the lipidic composition of the PM where membrane proteins are inserted. It has been postulated that PDs could be formed by lipid rafts, however no structural evidence has shown to visualize and analyse their lipid components. In this perspective article, we discuss proposed experiments to characterize lipid rafts and proteins in the PDs. By using atomic force microscopy (AFM) and mass spectrometry (MS) of purified PD vesicles it is possible to determine the presence of lipid rafts, specific bound proteins and the lipidomic profile of the PD under physiological conditions and after changing transport permeability. In addition, MS can determine the stoichiometry of intact membrane proteins inserted in lipid rafts. This will give novel insights into the role of membrane proteins and lipid rafts on the PD structure.

Keywords: mass spectrometry (MS), atomic force microscopy (AFM), lipid raft, membrane proteins, plasmodesmata (PDs)

\section{INTRODUCTION}

Plamodesmata (PDs) are nanopores connecting the cytoplasm of adjacent cells to facilitate intercellular communication. PDs generate symplastic communication pathways to transport small molecules below the size exclusion limit and selected bigger molecules. This in turn plays important roles for the cell fate and development, viral movement and transport of metabolites and miRNA (Bouyer et al., 2008; Lucas et al., 2009; Carlsbecker et al., 2010; Miyashima et al., 2011; Furuta et al., 2012)

PDs are structurally composed by a continuous plasma membrane (PM) between two adjacent cells with an axial highly packed central element of endoplasmic reticulum named desmotubule (Hepler, 1982; Tilney et al., 1991; Ding et al., 1992). The cell wall surrounding the channel is rich in pectin and depositions of $\beta$-1,3-glucan (callose) in the plasmodesma (PD) neck zone. To date there is consensus that these depositions regulate the molecular size of the transported molecules through PD (Roy et al., 1997; Botha and Cross, 2000; Levy et al., 2007; Guseman et al., 2010). In recent years, there have been considerable efforts carried out to determine the molecular composition of the $\mathrm{PD}$. In particular, using nano-LC ion trap MS/MS, Fernandez-Calvino et al. (2011) have done a proteomic analysis of PD vesicles and identified 1341 proteins that putatively belong to the PD (five of them were confirmed to be located inside the PD by confocal microscopy experiments), including glycosylphosphatidyl inositol (GPI)-anchored proteins. This family of proteins are anchored to the membrane and present high affinity for sterol containing lipid bilayers, which suggest that PD membrane could be forming lipid rafts (Mongrand et al., 2010; Salmon and Bayer, 2012). Membrane lipid rafts are defined as dynamical assemblies of sphingolipids and sterols (Lingwood and Simons, 2010). Supporting this hypothesis, Remorin protein, a lipid raft marker, was accumulated in the PD (Raffaele et al., 2009). Nevertheless, there is no experimental evidence showing the presence of lipid rafts in PDs, neither their lipid composition nor the location of intact specific membrane proteins. In this perspective article we propose a series of experimental approaches to get insights into these important issues by using atomic force microscopy (AFM) and mass spectrometry (MS).

\section{ATOMIC FORCE MICROSCOPY IMAGING}

AFM was invented (Binnig et al., 1986) to analyse only conductive samples and since then has advanced enormously specially with the design of new methodologies to study biological samples such as proteins, DNA and lipid bilayers under physiological conditions (Muller, 2008; Shahin and Barrera, 2008; Picas et al., 2012; Whited and Park, 2013). Basically AFM consists of a sharp tip around $10 \mathrm{~nm}$ radius attached to a flexible cantilever scanning over a sample to reconstruct its three dimensional topography. Because of the tip width further geometric deconvolution is needed to improve the sample lateral resolution ( $\mathrm{x}, \mathrm{y}$ plane) until nanometric dimension. On the other hand, the sample height $(\mathrm{z}$ plane) can achieve sub angstrom resolution based on finely tuning interaction force between the tip and sample. Depending upon samples properties, scanning can be done continuously (contact mode) or intermittently (tapping mode) for hard or soft samples respectively (for more details see Shahin and Barrera, 2008).

\section{AFM AND BIOLOGICAL MEMBRANES}

AFM has long been used to visualize lipid bilayers with a height resolution near to $0.1 \mathrm{~nm}$ (Mou et al., 1995; Dufrene et al., 1997; Grandbois et al., 1998; Hollars and Dunn, 1998; Rinia et al., 1999; 
McKiernan et al., 2000; Reviakine et al., 2000; Muresan and Lee, 2001) which has allowed dynamical detection of microdomains (rafts) in lipid bilayers and in native membranes in vitro (Dufrene et al., 1997; Giocondi et al., 2000, 2001, 2004; Yuan et al., 2002; Lawrence et al., 2003; Anderton et al., 2011). For example, using AFM (Lawrence et al., 2003) have studied in real time the effects of manipulating cholesterol levels in supported model membranes containing dioleoylphosphatidylcholine (DOPC) and sphingomyelin (SM). In absence of cholesterol, these membranes form small SM domains, which increase after cholesterol addition. An ordered and unique lipid raft domain is present at very high cholesterol concentrations, effect that is reversed once methyl- $\beta$-cyclodextrin (MßCD, cholesterol chelator) is applied. In addition, time-lapse AFM has been used to visualize dynamical processes in living cells, like extension and retraction of lamellipodium in MCF-7 cells (Li et al., 2013). Recent AFM studies on native membranes have proved the presence of lipid rafts in erythrocytes with a size of $100-300 \mathrm{~nm}$ and irregular shape and height of 2-4 nm above membrane bilayer (Cai et al., 2012). Orsini et al. (2012) have shown detergent-resistant membranes (DRMs) in human breast cancer cells with sizes of 100$500 \mathrm{~nm}$ and heights $1-2 \mathrm{~nm}$ above the PM. Furthermore, they demonstrated the presence of flotillin-1, a specific raft marker. Altogether, these evidence highlight the usefulness of the AFM technique in the lipid rafts analysis.

\section{MASS SPECTROMETRY OF MEMBRANE PROTEINS AND LIPID RAFTS}

MS determines both abundance and precise mass of biomolecules based on their ionization and mass/charge relationship in the gas phase (Barrera and Robinson, 2011). MS has emerged as a powerful tool to quantitatively analyse complex phospholipids such as those contained in lipid rafts, including glycerophospholipids and sphingolipids, from crude extracts (Pulfer and Murphy, 2003; Han and Gross, 2005). Interestingly, apart from proteomics information, MS has identified intact membrane proteins (Barrera et al., 2013), and also the stoichiometry and nature of lipids bound to them (Barrera et al., 2008, 2009). Altogether these data have shown that MS can provide structural aspects all the way through proteomics and lipidomics to stoichiometries of intact complexes.

A decade ago, a proteomic study identified 238 PM proteins from Arabidopsis thaliana (Alexandersson et al., 2004). They found 114 integral/GPI and 124 peripheral proteins; however only 180 out of the total proteins detected were classified as having a known function.

Lipid rafts in plants were suggested by the presence of a Triton X-100 insoluble PM fraction or DRM in tobacco cells. This fraction exhibited a different protein composition to that of PM, including GPI-anchored proteins (Peskan et al., 2000). Other proteins associated to DRMs comprise receptor-like kinases (RLKs), G-proteins (Morel et al., 2004), redox system proteins (Lefebvre et al., 2007) and stress associated proteins (Cacas et al., 2012). A proteomic strategy was developed to characterize membrane proteins associated to sterol containing DRMs fractions in $A$. thaliana (Kierszniowska et al., 2009). They found a considerable number of GPI-anchored proteins and other proteins with unknown function. Remorin protein, a molecular marker for lipid rafts in plants, has also been localized in the PD in Solanaceae family (Raffaele et al., 2009) In agreement to this, FernandezCalvino et al. (2011), via proteomics of the PD in A. thaliana, reported a variety of GPI-anchored proteins and remorin. Altogether, these data suggest that lipid rafts may constitute the PD.

Apart from lipid rafts, other cell membrane domains are tetraspanin-enriched microdomains (TEMs) (Hemler, 2005). Tetraspanins are integral transmembrane proteins which contain four transmembrane domains and two extracellular loops. Tetraspanins associates with cholesterol through a palmitate (Sacylation of the protein), and with gangliosides (Berditchevski, 2001; Boucheix and Rubinstein, 2001; Ono et al., 2001; Hemler, 2003, 2005). Most of their functions are involved in cell adhesion (to the extracellular matrix, other cells and pathogens), intercellular communication, membrane fusion and intracellular signaling. TEMs might enhance these processes by clustering functionally related molecules or by tightly packing a critical number of specific receptors at the PM (Yáñez-Mó et al., 2009). Lipid rafts and TEMs have similarities such as cholesterol enrichment (Le Naour et al., 2006) and localization in DRMs (Charrin et al., 2003). In contrast to lipid rafts, TEMs are mostly soluble in stronger non-ionic detergents, and resistant to cholesterol depletion (Claas et al., 2001), although partial disruption may be occasionally observed (Charrin et al., 2003). GPI-anchored proteins have not been detected in TEMs (Hemler, 2005). Based on tetraspanin identification and the absence of significant amounts of PM or endoplasmic reticulum markers in the PDs (Fernandez-Calvino et al., 2011), these nanopores could be constituted by highly specialized membrane microdomains that may contain TEMs. Indeed, it has been demonstrated the coalescence of lipid rafts and TEMs in human immunodeficiency virus type 1 (HIV-1) assembly sites on the PM by Förster resonance energy transfer (FRET) assay in living cells (Hogue et al., 2011). Furthermore, integrin-tetraspanin signaling complexes are partitioned into specific microdomains proximal to cholesterolrich lipid rafts (Berditchevski, 2001). Table 1 shows a summary of PD associated proteins with structural properties identified or hypothesized.

Mongrand et al. (2004) analyzed the lipidomics of DRMs isolated with Triton X-100 from tobacco PM. These microdomains mostly contained a sphyngolipid, named glucosylceramide (GluCer), and sterols such as stigmasterol, sitosterol, 24methylcholesterol, and cholesterol. Using TLC and gas chromatography/mass spectrometry (GC/MS), two phosphoinositides $\mathrm{PI}(4) \mathrm{P}$ y $\mathrm{PI}(4,5) \mathrm{P} 2$ were quantified in DRMs of PM from tobacco and BY-2 cells (Furt et al., 2010). Both phosphoinositides represent less than $5 \%$ of total lipids in tobacco PM; however its relative amount is increased 11 times in membrane rafts. In addition, structural phospholipids, such as phosphatidylcholine, phosphatidylethanolamine, phosphatidylinositol, phosphatidylserine, phosphatidic acid were not abundant in DRMs compared to the PM (Mongrand et al., 2004). Although MS has advanced the knowledge of lipid composition in membrane rafts (Mongrand et al., 2010), its application on the study of PD is still absent. 


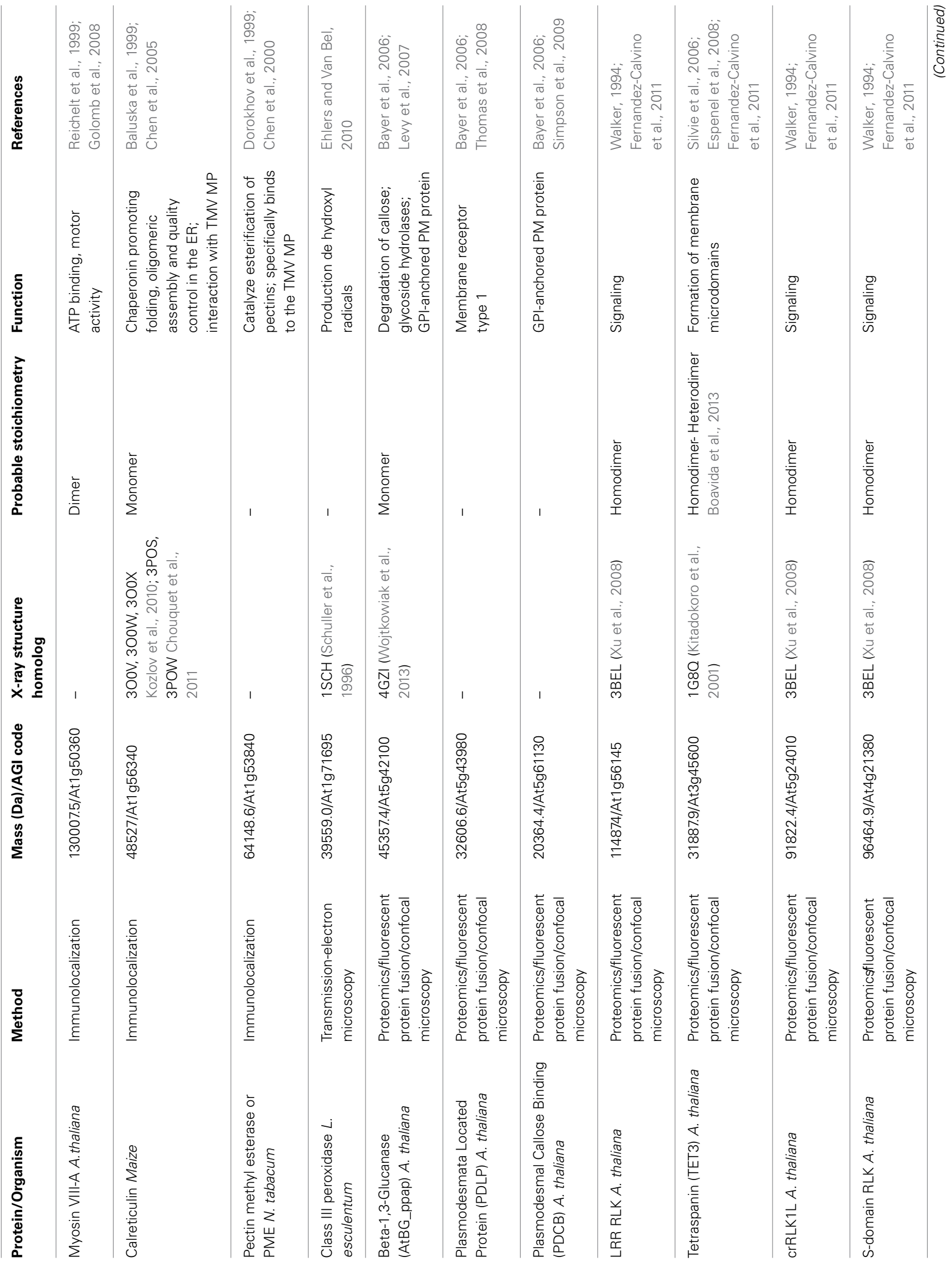




\section{CHARACTERIZATION OF THE PD MEMBRANE VIA AFM AND MS}

It has been widely accepted that complementary structural techniques including AFM and MS are needed to understand and predict the behavior of intact membrane proteins (Barrera and Edwardson, 2008; Barrera and Robinson, 2011). Additionally, AFM has proved to represent an excellent and unique choice to visualize the dynamics of lipid rafts (Henderson et al., 2004). In this perspective article we propose a combination of these methods to get novel insights into the protein and lipid composition of the $\mathrm{PD}$, in particular to determine the presence of lipid rafts, membrane protein stoichiometry and lipidomics. Considering that $\mathrm{PD}$ is a dynamic structure that responds to environmental stimuli, probably by changing its protein composition (Maule, 2008), we propose to evaluate in vitro purified PD vesicles under different physiological conditions. As stated in Figure 1A, Fernandez-Calvino et al., 2011 reported a methodology to purify PD vesicles, which are derived from membrane fractions without significant cell wall according to electron microscopy imaging. Further analysis by immunoblot of the samples confirmed the presence of PD proteins like PDLP1, and the absence of proteins associated to ER (BiP), Golgi (Membrine 11) and chloroplast (thylakoid P16).

Working with purified PD vesicles under physiological conditions (Figure 1A), AFM imaging could be applied to identify lipid rafts and TEMs based on topological parameters. Expected heights above plasma membrane for lipid rafts and TEMs are 1$4 \mathrm{~nm}$ (Cai et al., 2012; Orsini et al., 2012) and 5-6 nm (Brisson et al., 1983; Taylor and Robertson, 1984; Walz et al., 1995; Min et al., 2002, 2003), respectively. A putative AFM imaging of the $\mathrm{PD}$ vesicles is shown in Figure 1B. PM areas correspond to the minimal height of the vesicles (green color) which should be composed mostly by phospholipids. Lipid rafts correspond to flat domains of 1.5-2 $\mathrm{nm}$ above plasma membrane (yellow color). TEMs correspond to flat domains of 5-6 nm above plasma membrane (red color). Using MBCD on PD vesicles we could trigger a reorganization of the lipid rafts but not affecting TEMs (Claas et al., 2001; Giocondi et al., 2004) which would allow us to differentiate both membrane domains. Membrane proteins should be also observed in some areas of the lipid rafts and a variety of hypotheses could be tested. For example, remorin has been proposed as lipid raft molecular marker and has been found in the PD (Table 1). AFM imaging of this protein, based on its molecular weight, would induce a particle height less than $1 \mathrm{~nm}$ above the lipid raft (Figure 1B, upper panel). Remorin can also form homotrimers in vitro where each subunit is anchored to the membrane via C-terminal tails (Perraki et al., 2012). Therefore, assuming remorin (arrows, Figure 1B) can present different stoichiometries in the lipid rafts, AFM imaging could detect monomers (Figure 1B, ii) as well as trimers (Figure 1B, i) over the lipid raft flat surface. This is based only on approximate changes on molecular area or volume between both structures. As other proteins can be present in this membrane domain, another strategy is needed to corroborate the presence of this protein, which is force spectroscopy, using AFM tip functionalized (Dufrêne et al., 2013) with a specific anti-remorin antibody (Lefebvre et al., 2010). This technique consists of chemical modifications of the 
A

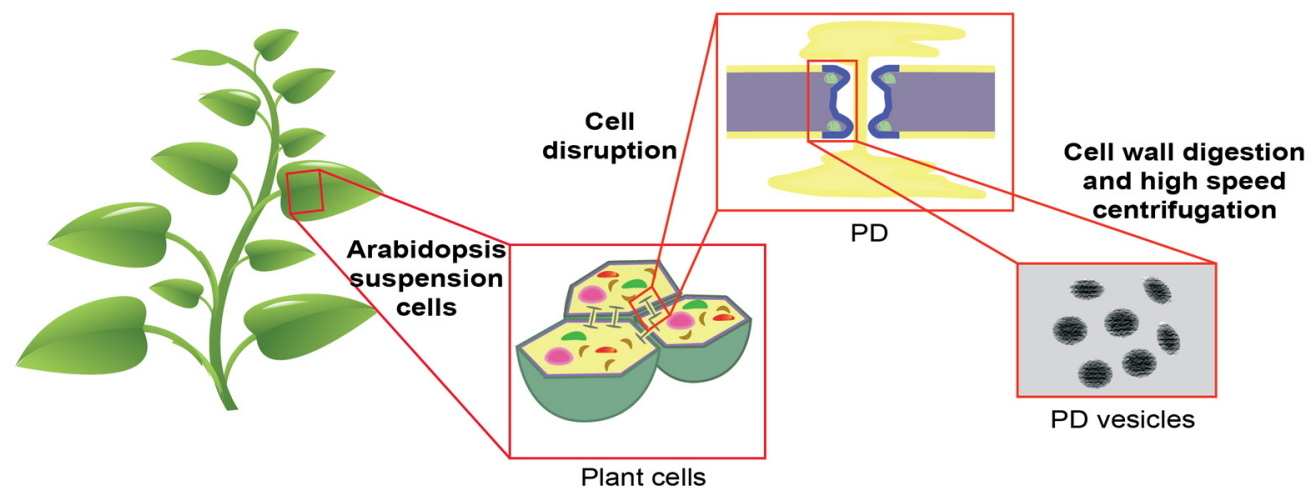

B

i) remorin

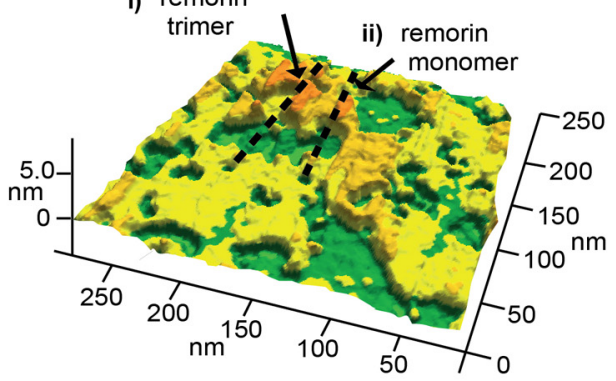

i

iii) TEM

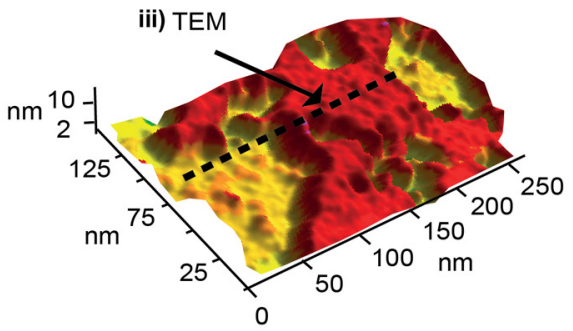

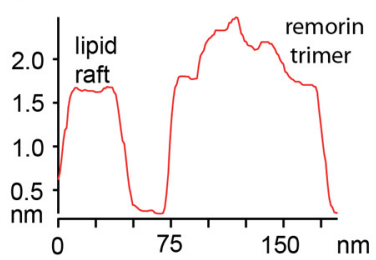

ii

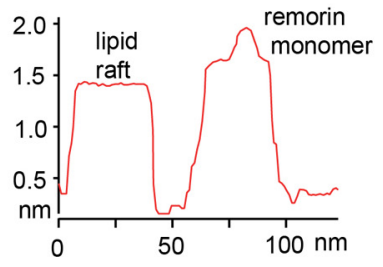

iii

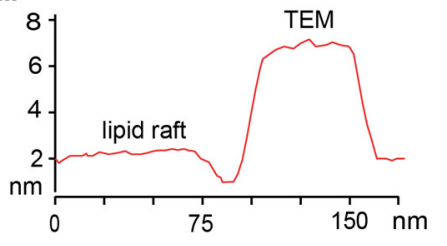

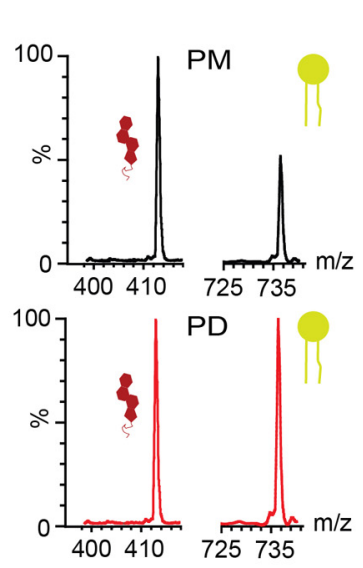

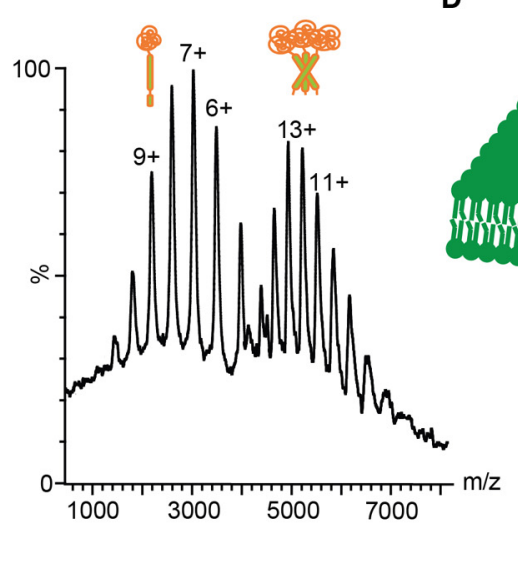

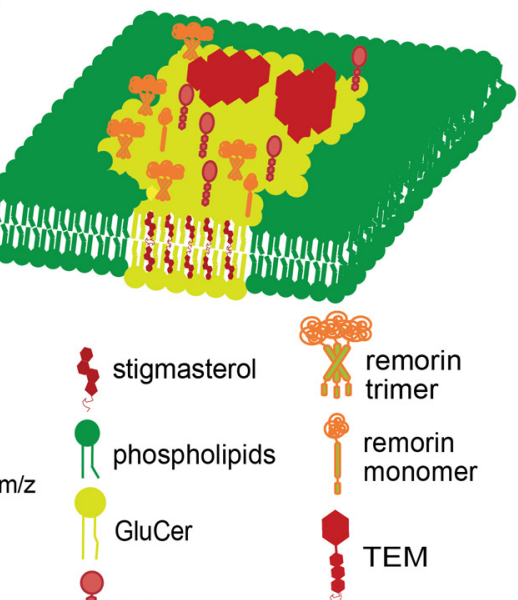

$\beta$-1,3-glucanase

FIGURE 1 | Combined AFM and MS methodology to characterize the PD protein and lipid structure. (A) Scheme of the purification of PD vesicles from A. thaliana suspension cells. (B) AFM imaging simulations of lipid rafts, TEMs and remorin in PD membrane. Upper panel, AFM imaging of PM (green) and lipid rafts (yellow) where remorin (arrows) monomer and trimers can be localized above lipid raft domains. Lower panel, AFM imaging of lipid rafts and
TEMs (red) is graphed. Right panels show a selection of cross section analyses (i-iii) for lipid and protein areas indicated as dashed lines in left panels. (C) Mass spectra simulations of stigmasterol and GluCer lipids from PM and PD are shown in black and red lines respectively (left panel). Mass spectra simulations of intact remorin showing monomeric and trimeric stoichiometries (right panel). (D) PD membrane model based on AFM and MS results. 
AFM tip to make a covalent bond between the tip surface and a protein/biomolecule (probe). In consequence this probe can interact specifically with the sample. In this case, at the single molecule event, a significant binding affinity on the remorin/antiremorin antibody complex would trigger an increase of the interaction force that subsequently can be transformed in dissociation constant (Le et al., 2011) for the remorin-antibody binding reaction. This figure can then be compared with traditional experiments to analyse binding such as isothermal calorimetry or surface plasmon resonance, usually used for much larger amount of sample. As stated previously, GPI-anchored proteins have been also proposed as lipid raft molecular markers in mammalian and plant cells (Sangiorgio et al., 2004; Mongrand et al., 2010) and therefore $B$ - 1,3-glucanase, localized in the PD (Table 1), is another alternative to study protein localization in the lipid rafts via AFM. Despite technical advances, visualization of PDs in living cells by AFM is currently precluded by the PD location, in the cell-to-cell physical communication that is not accessible to the AFM tip.

To characterize the lipidomics of PD vesicles we could use Liquid Chromatography-MS/MS. Based on Mongrand et al. (2004), it is expected that GluCer would be distributed in DRMs rather than in PM with a peak at $736.6 \mathrm{~m} / \mathrm{z}$. On the other hand, stigmasterol (peak at $412.7 \mathrm{~m} / \mathrm{z}$ ) would be in similar proportions in PM and lipid rafts. Figure 1C shows mass spectra of both lipid species. Hence MS of PM lipids would show a larger stigmasterol/GluCer intensity ratio (black spectra in Figure 1C) compared to a MS of PD lipids (red spectra in Figure 1C) from plant cell samples. As recently demonstrated, MS has been used to determine the stoichiometry of intact membrane protein complexes as well as to identify post-translational modifications and small molecules bound to membrane proteins. This can be done by removing the protective micelle environment via collisioninduced dissociation with neutral gas molecules inside mass spectrometer that results in the releasing of intact membrane proteins (Barrera and Robinson, 2011; Barrera et al., 2013). Using MS on solubilized PD vesicles, it would be possible to determine the stoichiometry of remorin and test whether or not form monomers and/or trimers (Figure 1C), and therefore corroborate the data obtained by AFM imaging (see above). The measurement can be very accurate within Da resolution. In addition, the same sample could be digested by trypsin in proteomic experiments to verify possible protein modifications.

In our experimental design we have proposed to work under different physiological conditions to analyse variations on $\mathrm{PD}$ constitution and conformation in response to environmental stimuli. It is reported that changes on PD permeability by pathogen infection have been observed after increasing callose deposition on the cell wall near to the PD neck, which reduces channel diameter (Zavaliev et al., 2011). In addition, the cellular redox state regulates PD permeability. Mutations in mitochondrial RNA helicase, ise1, (Stonebloom et al., 2009), and thioredoxin type m3, gat1, (Benitez-Alfonso and Jackson, 2009), induce an increase of reactive oxygen species (ROS) in plant cells. However, both mutants have opposite effects on the PD permeability, while ise 1 increases permeability, gat1 decreases it. More recently, $\mathrm{H}_{2} \mathrm{O}_{2}$ treatments display a byphasic effect on PD permeability, where $0.6 \mathrm{mM}$ and $6 \mathrm{mM} \mathrm{H}_{2} \mathrm{O}_{2}$ produce a twofold increment and total abolition, respectively (Rutschow et al., 2011). These results confirm that redox state controls the PD permeability and makes it an important candidate to modulate the lipid and protein abundance in the PD. Therefore, we propose to incubate cultured plant cells with low $(0.6 \mathrm{mM})$ and high $(6 \mathrm{mM}) \mathrm{H}_{2} \mathrm{O}_{2}$ concentrations prior to $\mathrm{PD}$ vesicles purification. There is evidence showing that the plasmodesmal aperture is regulated by callose deposition at the neck region (Simpson et al., 2009; Zavaliev et al., 2011). Therefore, an increase in permeability induced by treatment with low concentrations of $\mathrm{H}_{2} \mathrm{O}_{2}$ could be mediated in part by the increase in the abundance of $\beta-1,3$ glucanase (protein that degrades callose) and/or a decrease in the abundance of plasmodesmal callose binding protein (PDCB1). It has been shown that PDCB1 overexpression augmented callose accumulation resulting in a reduction of green fluorescent protein (GFP) diffusion. Therefore, there is an association between PDCB-mediated callose deposition and plant cell-to-cell communication (Simpson et al., 2009). An opposite effect would be observed after high $\mathrm{H}_{2} \mathrm{O}_{2}$ concentrations. Interestingly, protein clustering in lipid rafts depends on cholesterol presence (Simons and Toomre, 2000). Moreover oxygenated derivatives of cholesterol (oxysterols) can be generated by ROS (Terao, 2014) and trigger a dynamic redistribution of lipids from lipid rafts (Bacia et al., 2005). For example, if stigmasterol is similarly modified, an oxysterol signal would appear in the MS lipidomics analysis and probably would affect the size and dynamics of the lipid raft imaged by AFM. These evidence suggest that cellular redox states may change PD permeability thorough lipid and protein modifications, which can be studied by traditional lipidomics and proteomics in MS experiments.

These proposed experiments would allow us to postulate a structural PD membrane model (Figure 1D) where specific lipid and protein components are responsible for the mechanisms underlying biomolecule transport.

In this perspective article, we have discussed the potential use of complementary state-of-the-art AFM and MS to characterize the PD lipid and protein structure from native conditions. We envisage that novel studies in the near future combining this with plant genomics could lead to an integrative view on the PD role for cell-to-cell communication throughout plant development.

\section{ACKNOWLEDGMENTS}

Funding from Fondo Nacional de Desarrollo Científico y Tecnológico (FONDECYT) \#1120169, National Commission of Science and Technology (CONICYT) \#PIA-ACT1108 and the Millennium Scientific Initiative (Ministerio de Economía, Fomento y Turismo) \#P10-035-F is acknowledged. Dr. Andrea Gómez for critical reading of the manuscript.

\section{REFERENCES}

Alexandersson, E., Saalbach, G., Larsson, C., and Kjellbom, P. (2004). Arabidopsis plasma membrane proteomics identifies components of transport, signal transduction and membrane trafficking. Plant Cell Physiol. 45, 1543-1556. doi: $10.1093 / \mathrm{pcp} / \mathrm{pch} 209$

Anderton, C. R., Lou, K., Weber, P. K., Hutcheon, I. D., and Kraft, M. L. (2011). Correlated AFM and NanoSIMS imaging to probe cholesterol-induced changes in phase behavior and non-ideal mixing in ternary lipid membranes. 
Biochim. Biophys. Acta 1808, 307-315. doi: 10.1016/j.bbamem.2010. 09.016

Bacia, K., Schwille, P., and Kurzchalia, T. (2005). Sterol structure determines the separation of phases and the curvature of the liquid-ordered phase in model membranes. Proc. Natl. Acad. Sci. U.S.A. 102, 3272-3277. doi: 10.1073/pnas.0408215102

Baluska, F., Samaj, J., Napier, R., and Volkmann, D. (1999). Maize calreticulin localizes preferentially to plasmodesmata in root apex. Plant J. 19, 481-488. doi: 10.1046/j.1365-313X.1999.00530.x

Barrera, N. P., Di Bartolo, N., Booth, P. J., and Robinson, C. V. (2008). Micelles protect membrane complexes from solution to vacuum. Science 321, 243-246. doi: 10.1126/science. 1159292

Barrera, N. P., and Edwardson, J. M. (2008). The subunit arrangement and assembly of ionotropic receptors. Trends Neurosci. 31, 569-576. doi: 10.1016/j.tins.2008.08.001

Barrera, N. P., Isaacson, S. C., Zhou, M., Bavro, V. N., Welch, A., Schaedler, T. A., et al. (2009). Mass spectrometry of membrane transporters reveals subunit stoichiometry and interactions. Nat. Methods 6, 585-587. doi: 10.1038/nmeth.1347

Barrera, N. P., and Robinson, C. V. (2011). Advances in the mass spectrometry of membrane proteins: from individual proteins to intact complexes. Annu. Rev. Biochem. 80, 247-271. doi: 10.1146/annurev-biochem-062309-093307

Barrera, N. P., Zhou, M., and Robinson, C. V. (2013). The role of lipids in defining membrane protein interactions: insights from mass spectrometry. Trends Cell Biol. 23, 1-8. doi: 10.1016/j.tcb.2012.08.007

Bayer, E. M., Bottrill, A. R., Walshaw, J., Vigouroux, M., Naldrett, M. J., Thomas, C. L., et al. (2006). Arabidopsis cell wall proteome defined using multidimensional protein identification technology. Proteomics 6, 301-311. doi: 10.1002/pmic. 200500046

Benitez-Alfonso, Y., and Jackson, D. (2009). Redox homeostasis regulates plasmodesmal communication in Arabidopsis meristems. Plant Signal. Behav. 4, 655-659. doi: 10.4161/psb.4.7.8992

Berditchevski, F. (2001). Complexes of tetraspanins with integrins: more than meets the eye. J. Cell Sci. 114, 4143-4151.

Binnig, G., Quate, F., and Gerber, C. (1986). Atomic force microscope. Phys. Rev. Lett. 56, 930-934. doi: 10.1103/PhysRevLett.56.930

Blackman, L. M., and Overall, R. L. (1998). Immunolocalisation of the cytoskeleton to plasmodesmata of Chara corallina. Plant J. 14, 733-741. doi: 10.1046/j.1365313x.1998.00161.x

Boavida, L. C., Qin, P., Broz, M., Becker, J. D., and Mccormick, S. (2013). Arabidopsis tetraspanins are confined to discrete expression domains and cell types in reproductive tissues and form homo- and heterodimers when expressed in yeast. Plant Physiol. 163, 696-712. doi: 10.1104/pp.113.216598

Botha, C. E., and Cross, R. H. (2000). Towards reconciliation of structure with function in plasmodesmata-who is the gatekeeper? Micron 31, 713-721. doi: 10.1016/S0968-4328(99)00108-0

Boucheix, C., and Rubinstein, E. (2001). Tetraspanins. Cell. Mol. Life Sci. 58, 1189-1205. doi: 10.1007/PL00000933

Bouyer, D., Geier, F., Kragler, F., Schnittger, A., Pesch, M., Wester, K., et al. (2008). Two-dimensional patterning by a trapping/depletion mechanism: the role of TTG1 and GL3 in Arabidopsis trichome formation. PLoS Biol. 6:e141. doi: 10.1371/journal.pbio.0060141

Brisson, A., Wade, R. H., and Moody, M. F. (1983). Three-dimensional structure of luminal plasma membrane protein from urinary bladder. J. Mol. Biol. 166, 21-36. doi: 10.1016/S0022-2836(83)80048-5

Cacas, J.-L., Furt, F., Le Guédard, M., Schmitter, J.-M., Buré, C., Gerbeau-Pissot, P., et al. (2012). Lipids of plant membrane rafts. Prog. Lipid Res. 51, 272-299. doi: 10.1016/j.plipres.2012.04.001

Cai, M., Zhao, W., Shang, X., Jiang, J., Ji, H., Tang, Z., et al. (2012). Direct evidence of lipid rafts by in situ atomic force microscopy. Small 8, 1243-1250. doi: 10.1002/smll.201102183

Carlsbecker, A., Lee, J.-Y., Roberts, C. J., Dettmer, J., Lehesranta, S., Zhou, J., et al. (2010). Cell signalling by microRNA165/6 directs gene dose-dependent root cell fate. Nature 465, 316-321. doi: 10.1038/nature08977

Charrin, S., Manié, S., Thiele, C., Billard, M., Gerlier, D., Boucheix, C., et al. (2003). A physical and functional link between cholesterol and tetraspanins. Eur. J. Immunol. 33, 2479-2489. doi: 10.1002/eji.200323884

Chen, M. H., Sheng, J., Hind, G., Handa, A. K., and Citovsky, V. (2000). Interaction between the tobacco mosaic virus movement protein and host cell pectin methylesterases is required for viral cell-to-cell movement. EMBO J. 19, 913-920. doi: 10.1093/emboj/19.5.913

Chen, M.-H., Tian, G.-W., Gafni, Y., Citovsky, V., Biology, C., and Brook, S. (2005). Effects of calreticulin on viral cell-to-cell movement 1. Plant Physiol. 138, 1866-1876. doi: 10.1104/pp.105.064386

Chouquet, A., Païdassi, H., Ling, W. L., Frachet, P., Houen, G., Arlaud, G. J., et al. (2011). X-ray structure of the human calreticulin globular domain reveals a peptide-binding area and suggests a multi-molecular mechanism. PLOS ONE 6:e17886. doi: 10.1371/journal.pone.0017886

Claas, C., Stipp, C. S., and Hemler, M. E. (2001). Evaluation of prototype transmembrane 4 superfamily protein complexes and their relation to lipid rafts. J. Biol. Chem. 276, 7974-7984. doi: 10.1074/jbc.M008650200

Ding, B., Turgeon, R., and Parthasarathy, M. V. (1992). Substructure of freezesubstituted plasmodesmata. Protoplasma 169, 28-41. doi: 10.1007/BF01343367

Dorokhov, Y. L., Mäkinen, K., Frolova, O. Y., Merits, A., Saarinen, J., Kalkkinen, N., et al. (1999). A novel function for a ubiquitous plant enzyme pectin methylesterase: the host-cell receptor for the tobacco mosaic virus movement protein. FEBS Lett. 461, 223-228. doi: 10.1016/S0014-5793(99) 01447-7

Dufrene, Y. F., Barger, W. R., Green, J. B. D., and Lee, G. U. (1997). Nanometer-scale surface properties of mixed phospholipid monolayers and bilayers. Langmuir 13, 4779-4784. doi: 10.1021/la970221r

Dufrêne, Y. F., Martínez-Martín, D., Medalsy, I., Alsteens, D., and Müller, D. J. (2013). Multiparametric imaging of biological systems by force-distance curve-based AFM. Nat. Methods 10, 847-854. doi: 10.1038/nmeth.2602

Ehlers, K., and Van Bel, A. J. E. (2010). Dynamics of plasmodesmal connectivity in successive interfaces of the cambial zone. Planta 231, 371-385. doi: 10.1007/s00425-009-1046-8

Espenel, C., Margeat, E., Dosset, P., Arduise, C., Le Grimellec, C., Royer, C. A., et al. (2008). Single-molecule analysis of CD9 dynamics and partitioning reveals multiple modes of interaction in the tetraspanin web. J. Cell Biol. 182, 765-776. doi: $10.1083 /$ jcb.200803010

Faulkner, C., Petutschnig, E., Benitez-Alfonso, Y., Beck, M., Robatzek, S., Lipka, V., et al. (2013). LYM2-dependent chitin perception limits molecular flux via plasmodesmata. Proc. Natl. Acad. Sci. U.S.A. 110, 9166-9170. doi: 10.1073/pnas. 1203458110

Fernandez-Calvino, L., Faulkner, C., Walshaw, J., Saalbach, G., Bayer, E., BenitezAlfonso, Y., et al. (2011). Arabidopsis plasmodesmal proteome. PLoS ONE 6:e18880. doi: 10.1371/journal.pone.0018880

Furt, F., König, S., Bessoule, J.-J., Sargueil, F., Zallot, R., Stanislas, T., et al. (2010). Polyphosphoinositides are enriched in plant membrane rafts and form microdomains in the plasma membrane. Plant Physiol. 152, 2173-2187. doi: 10.1104/pp.109.149823

Furuta, K., Lichtenberger, R., and Helariutta, Y. (2012). The role of mobile small RNA species during root growth and development. Curr. Opin. Cell Biol. 24, 211-216. doi: 10.1016/j.ceb.2011.12.005

Giocondi, M.-C., Milhiet, P. E., Dosset, P., and Le Grimellec, C. (2004). Use of cyclodextrin for AFM monitoring of model raft formation. Biophys. J. 86, 861-869. doi: 10.1016/S0006-3495(04)74161-2

Giocondi, M. C., Vié, V., Lesniewska, E., Goudonnet, J. P., and Le Grimellec, C. (2000). In situ imaging of detergent-resistant membranes by atomic force microscopy. J. Struct. Biol. 131, 38-43. doi: 10.1006/jsbi.2000.4266

Giocondi, M. C., Vie, V., Lesniewska, E., Milhiet, J. P., Allmang, M., and Le Grimellec, C. (2001). phase topology and growth of single domains in lipid bilayers. Langmuir 17, 1653-1659. doi: 10.1021/la0012135

Golomb, L., Abu-Abied, M., Belausov, E., and Sadot, E. (2008). Different subcellular localizations and functions of Arabidopsis myosin VIII. BMC Plant Biol. 8:3. doi: 10.1186/1471-2229-8-3

Grandbois, M., Clausen-Schaumann, H., and Gaub, H. (1998). Atomic force microscope imaging of phospholipid bilayer degradation by phospholipase A2. Biophys. J. 74, 2398-2404. doi: 10.1016/S0006-3495(98) 77948-2

Guseman, J. M., Lee, J. S., Bogenschutz, N. L., Peterson, K. M., Virata, R. E., Xie, B., et al. (2010). Dysregulation of cell-to-cell connectivity and stomatal patterning by loss-of-function mutation in Arabidopsis chorus (glucan synthase-like 8). Development 137, 1731-1741. doi: 10.1242/dev.049197

Han, X., and Gross, R. W. (2005). Shotgun lipidomics: electrospray ionization mass spectrometric analysis and quantitation of cellular lipidomes directly from 
crude extracts of biological samples. Mass Spectrom. Rev. 24, 367-412. doi: $10.1002 /$ mas. 20023

Hemler, M. E. (2003). Tetraspanin proteins mediate cellular penetration, invasion, and fusion events and define a novel type of membrane microdomain. Annu. Rev. Cell Dev. Biol. 19, 397-422. doi: 10.1146/annurev.cellbio.19.111301.153609

Hemler, M. E. (2005). Tetraspanin functions and associated microdomains. Nat. Rev. Mol. Cell Biol. 6, 801-811. doi: 10.1038/nrm1736

Henderson, R. M., Edwardson, J. M., Geisse, N. A., and Saslowsky, D. E. (2004). Lipid rafts: feeling is believing. Physiology 19, 39-43. doi: 10.1152/nips.01505.2003

Hepler, P. K. (1982). Endoplasmic reticulum in the formation of the cell plate and plasmodesmata. Protoplasma 111, 121-133. doi: 10.1007/BF01282070

Hogue, I. B., Grover, J. R., Soheilian, F., Nagashima, K., and Ono, A. (2011). Gag induces the coalescence of clustered lipid rafts and tetraspanin-enriched microdomains at HIV-1 assembly sites on the plasma membrane. J. Virol. 85, 9749-9766. doi: 10.1128/JVI.00743-11

Hollars, C. W., and Dunn, R. C. (1998). Submicron structure in L-alphadipalmitoylphosphatidylcholine monolayers and bilayers probed with confocal, atomic force, and near-field microscopy. Biophys. J. 75, 342-353. doi: 10.1016/S0006-3495(98)77518-6

Kierszniowska, S., Seiwert, B., and Schulze, W. X. (2009). Definition of arabidopsis sterol-rich membrane microdomains by differential treatment with methyl- $\beta$ cyclodextrin and quantitative proteomics. Mol. Cell. Proteomics 8, 612-623. doi: 10.1074/mcp.M800346-MCP200

Kitadokoro, K., Bordo, D., Galli, G., Petracca, R., Falugi, F., Abrignani, S., et al. (2001). CD81 extracellular domain 3D structure: insight into the tetraspanin superfamily structural motifs. EMBO J. 20, 12-18. doi: 10.1093/emboj/20.1.12

Kozlov, G., Pocanschi, C. L., Rosenauer, A., Bastos-Aristizabal, S., Gorelik, A., Williams, D. B., et al. (2010). Structural basis of carbohydrate recognition by calreticulin. J. Biol. Chem. 285, 38612-38620. doi: 10.1074/jbc.M110.168294

Lawrence, J. C., Saslowsky, D. E., Edwardson, J. M., and Henderson, R. M. (2003). Real-time analysis of the effects of cholesterol on lipid raft behavior using atomic force microscopy. Biophys. J. 84, 1827-1832. doi: 10.1016/S00063495(03)74990-X

Le, D. T., Guérardel, Y., Loubière, P., Mercier-Bonin, M., and Dague, E. (2011). Measuring kinetic dissociation/association constants between lactococcus lactis bacteria and mucins using living cell probes. Biophys. J. 101, 2843-2853. doi: 10.1016/j.bpj.2011.10.034

Lefebvre, B., Furt, F., Hartmann, M.-A., Michaelson, L. V., Carde, J.-P., SargueilBoiron, F., et al. (2007). Characterization of lipid rafts from medicago truncatula root plasma membranes: a proteomic study reveals the presence of a raft-associated redox system. Plant Physiol. 144, 402-418. doi: 10.1104/pp.106.094102

Lefebvre, B., Timmers, T., Mbengue, M., Moreau, S., Hervé, C., Tóth, K., et al. (2010). A remorin protein interacts with symbiotic receptors and regulates bacterial infection. Proc. Natl. Acad. Sci. U.S.A. 107, 2343-2348. doi: 10.1073/pnas.0913320107

Le Naour, F., André, M., Boucheix, C., and Rubinstein, E. (2006). Membrane microdomains and proteomics: lessons from tetraspanin microdomains and comparison with lipid rafts. Proteomics 6, 6447-6454. doi: 10.1002/pmic.200600282

Levy, A., Erlanger, M., Rosenthal, M., and Epel, B. L. (2007). A plasmodesmataassociated beta-1,3-glucanase in Arabidopsis. Plant J. 49, 669-682. doi: 10.1111/j.1365-313X.2006.02986.x

Li, M., Liu, L., Xi, N., Wang, Y., Dong, Z., Xiao, X., et al. (2013). Atomic force microscopy imaging of live mammalian cells. Sci. China Life Sci. 56, 811-817. doi: 10.1007/s11427-013-4532-y

Lingwood, D., and Simons, K. (2010). Lipid rafts as a membrane- organizing principle. Science 327, 46-50. doi: 10.1126/science.1174621

Lucas, W. J., Ham, B.-K., and Kim, J.-Y. (2009). Plasmodesmata-bridging the gap between neighboring plant cells. Trends Cell Biol. 19, 495-503. doi: 10.1016/j.tcb.2009.07.003

Maule, A. J. (2008). Plasmodesmata: structure, function and biogenesis. Curr. Opin. Plant Biol. 11, 680-686. doi: 10.1016/j.pbi.2008.08.002

McKiernan, A. E., Ratto, T. V., and Longo, M. L. (2000). Domain growth, shapes, and topology in cationic lipid bilayers on mica by fluorescence and atomic force microscopy. Biophys. J. 79, 2605-2615. doi: 10.1016/S0006-3495(00)76499-X

Min, G., Stolz, M., Zhou, G., Liang, F., Sebbel, P., Stoffler, D., et al. (2002). Localization of uroplakin Ia, the urothelial receptor for bacterial adhesin FimH, on the six inner domains of the $16 \mathrm{~nm}$ urothelial plaque particle. J. Mol. Biol. 317, 697-706. doi: 10.1006/jmbi.2002.5442

Min, G., Zhou, G., Schapira, M., Sun, T.-T., and Kong, X.-P. (2003). Structural basis of urothelial permeability barrier function as revealed by Cryo-EM studies of the $16 \mathrm{~nm}$ uroplakin particle. J. Cell Sci. 116, 4087-4094. doi: 10.1242/jcs.00811

Miyashima, S., Koi, S., Hashimoto, T., and Nakajima, K. (2011). Non-cellautonomous microRNA165 acts in a dose-dependent manner to regulate multiple differentiation status in the Arabidopsis root. Development 138, 2303-2313. doi: 10.1242/dev.060491

Mongrand, S., Morel, J., Laroche, J., Claverol, S., Carde, J.-P., Hartmann, M.-A., et al. (2004). Lipid rafts in higher plant cells: purification and characterization of Triton X-100-insoluble microdomains from tobacco plasma membrane. J. Biol. Chem. 279, 36277-36286. doi: 10.1074/jbc.M403440200

Mongrand, S., Stanislas, T., Bayer, E. M. F., Lherminier, J., and Simon-Plas, F. (2010). Membrane rafts in plant cells. Trends Plant Sci. 15, 656-663. doi: 10.1016/j.tplants.2010.09.003

Morel, J., Fromentin, J., Blein, J.-P., Simon-Plas, F., and Elmayan, T. (2004). Rac regulation of NtrbohD, the oxidase responsible for the oxidative burst in elicited tobacco cell. Plant J. 37, 282-293. doi: 10.1046/j.1365-313X.2003.01957.x

Mou, J., Yang, J., and Shao, Z. (1995). Atomic force microscopy of cholera toxin B-oligomers bound to bilayers of biologically relevant lipids. J. Mol. Biol. 248, 507-512. doi: 10.1006/jmbi.1995.0238

Muller, D. J. (2008). AFM: a nanotool in membrane biology. Biochemistry 47, 7986-7998. doi: 10.1021/bi800753x

Muresan, A. S., and Lee, K. Y. C. (2001). Shape evolution of lipid bilayer patches adsorbed on mica: an atomic force microscopy study. J. Phys. Chem. B 105, 852-855. doi: 10.1021/jp001813c

Ono, M., Handa, K., Sonnino, S., Withers, D. A., Nagai, H., and Hakomori, S.I. (2001). GM3 ganglioside inhibits CD9-facilitated haptotactic cell motility: coexpression of GM3 and CD9 is essential in the downregulation of tumor cell motility and malignancy $\dagger$. Biochemistry 40, 6414-6421. doi: 10.1021/bi0101998

Orsini, F., Cremona, A., Arosio, P., Corsetto, P. A., Montorfano, G., Lascialfari, A., et al. (2012). Atomic force microscopy imaging of lipid rafts of human breast cancer cells. Biochim. Biophys. Acta 1818, 2943-2949. doi: 10.1016/j.bbamem.2012.07.024

Pak, J. E., Arnoux, P., Zhou, S., Sivarajah, P., Satkunarajah, M., Xing, X., et al. (2006). X-ray crystal structure of leukocyte type core $2 \beta 1,6-\mathrm{N}$ Acetylglucosaminyltransferase: evidence for a convergence of metal ionindependent glycosyltransferase mechanism. J. Biol. Chem. 281, 26693-26701. doi: 10.1074/jbc.M603534200

Perraki, A., Cacas, J.-L., Crowet, J.-M., Lins, L., Castroviejo, M., German-Retana, S., et al. (2012). Plasma membrane localization of solanum tuberosum remorin from group 1, homolog 3 is mediated by conformational changes in a novel cterminal anchor and required for the restriction of potato virus $\mathrm{X}$ movement]. Plant Physiol. 160, 624-637. doi: 10.1104/pp.112.200519

Peskan, T., Westermann, M., and Oelmüller, R. (2000). Identification of low-density Triton X-100-insoluble plasma membrane microdomains in higher plants. Eur. J. Biochem. 267, 6989-6995. doi: 10.1046/j.1432-1327.2000.01776.x

Picas, L., Milhiet, P.-E., and Hernández-Borrell, J. (2012). Atomic force microscopy: a versatile tool to probe the physical and chemical properties of supported membranes at the nanoscale. Chem. Phys. Lipids 165, 845-860. doi: 10.1016/j.chemphyslip.2012.10.005

Pulfer, M., and Murphy, R. C. (2003). Electrospray mass spectrometry of phospholipids. Mass Spectrom. Rev. 22, 332-364. doi: 10.1002/mas.10061

Raffaele, S., Bayer, E., Lafarge, D., Cluzet, S., German Retana, S., Boubekeur, T., et al. (2009). Remorin, a solanaceae protein resident in membrane rafts and plasmodesmata, impairs potato virus X movement. Plant Cell 21, 1541-1555. doi: 10.1105/tpc.108.064279

Reichelt, S., Knight, A. E., Hodge, T. P., Baluska, F., Samaj, J., Volkmann, D., et al. (1999). Characterization of the unconventional myosin VIII in plant cells and its localization at the post-cytokinetic cell wall. Plant J. 19, 555-567. doi: 10.1046/j.1365-313X.1999.00553.x

Reviakine, I., Simon, A., and Brisson, A. (2000). Effect of $\mathrm{Ca}^{2+}$ on the morphology of mixed DPPC-DOPS supported phospholipid bilayers. Langmuir 16, 1473-1477. doi: 10.1021/la990806g

Rinia, H. A., Demel, R. A., Van Der Eerden, J. P., and De Kruijff, B. (1999). Blistering of langmuir-blodgett bilayers containing anionic phospholipids as observed by atomic force microscopy. Biophys. J. 77, 1683-1693. doi: 10.1016/S00063495(99)77015-3 
Roy, S., Watada, A. E., and Wergin, W. P. (1997). Characterization of the cell wall microdomain surrounding plasmodesmata in apple fruit. Plant Physiol. 114, 539-547.

Rutschow, H. L., Baskin, T. I., and Kramer, E. M. (2011). Regulation of solute flux through plasmodesmata in the root meristem. Plant Physiol. 155, 1817-1826. doi: 10.1104/pp.110.168187

Salmon, M. S., and Bayer, E. M. F. (2012). Dissecting plasmodesmata molecular composition by mass spectrometry-based proteomics. Front. Plant Sci. 3:307. doi: 10.3389/fpls.2012.00307

Sangiorgio, V., Pitto, M., Palestini, P., and Masserini, M. (2004). GPI-anchored proteins and lipid rafts. Ital. J. Biochem. 53, 98-111.

Schuller, D. J., Ban, N., Huystee, R. B., McPherson, A., and Poulos, T. L. (1996). The crystal structure of peanut peroxidase. Structure 4, 311-321. doi: 10.1016/S0969-2126(96)00035-4

Shahin, V., and Barrera, N. P. (2008). Providing unique insight into cell biology via atomic force microscopy. Int. Rev. Cytol. 265, 227-252. doi: 10.1016/S00747696(07)65006-2

Silvie, O., Charrin, S., Billard, M., Franetich, J.-F., Clark, K. L., Van Gemert, G.-J., et al. (2006). Cholesterol contributes to the organization of tetraspaninenriched microdomains and to CD81-dependent infection by malaria sporozoites. J. Cell Sci. 119, 1992-2002. doi: 10.1242/jcs.02911

Simons, K., and Toomre, D. (2000). Lipid rafts and signal transduction. Nat. Rev. Mol. Cell Biol. 1, 31-39. doi: 10.1038/35036052

Simpson, C., Thomas, C., Findlay, K., Bayer, E., and Maule, A. J. (2009). An Arabidopsis GPI-anchor plasmodesmal neck protein with callose binding activity and potential to regulate cell-to-cell trafficking. Plant Cell 21, 581-594. doi: 10.1105/tpc. 108.060145

Stonebloom, S., Burch-Smith, T., Kim, I., Meinke, D., Mindrinos, M., and Zambryski, P. (2009). Loss of the plant DEAD-box protein ISE1 leads to defective mitochondria and increased cell-to-cell transport via plasmodesmata. Proc. Natl. Acad. Sci. U.S.A. 106, 17229-17234. doi: 10.1073/pnas.0909229106

Taylor, K. A., and Robertson, J. D. (1984). Analysis of the three-dimensional structure of the urinary bladder epithelial cell membranes. J. Ultrastruct. Res. 87, 23-30. doi: 10.1016/S0022-5320(84)90113-8

Terao, J. (2014). "Cholesterol hydroperoxides and their degradation mechanism," in Lipid Hydroperoxide-Derived Modification of Biomolecules, Vol. 77, ed Y. Kato (Netherlands: Springer), 83-91. doi: 10.1007/978-94-007-7920-4_7

Thomas, C. L., Bayer, E. M., Ritzenthaler, C., Fernandez-Calvino, L., and Maule, A. J. (2008). Specific targeting of a plasmodesmal protein affecting cell-to-cell communication. PLoS Biol. 6:e7. doi: 10.1371/journal.pbio.0060007

Tilney, L. G., Cooke, T. J., Connelly, P. S., and Tilney, M. S. (1991). The structure of plasmodesmata as revealed by plasmolysis, detergent extraction, and protease digestion. J. Cell Biol. 112, 739-747. doi: 10.1083/jcb.112.4.739

Walker, J. (1994). Structure and function of the receptor-like protein kinases of higher plants. Plant Mol. Biol. 26, 1599-1609. doi: 10.1007/BF00016492
Walz, T., Häner, M., Wu, X.-R., Henn, C., Engel, A., Sun, T.-T., et al. (1995). Towards the molecular architecture of the asymmetric unit membrane of the mammalian urinary bladder epithelium: a closed "Twisted Ribbon" structure. J. Mol. Biol. 248, 887-900. doi: 10.1006/jmbi.1995.0269

Whited, A. M., and Park, P. S. H. (2013). Atomic force microscopy: a multifaceted tool to study membrane proteins and their interactions with ligands. Biochim. Biophys. 1838, 56-68. doi: 10.1016/j.bbamem.2013.04.011

Wojtkowiak, A., Witek, K., Hennig, J., and Jaskolski, M. (2013). Structures of an active-site mutant of a plant 1,3- $\beta$-glucanase in complex with oligosaccharide products of hydrolysis. Acta Crystallogr. D Biol. Crystallogr. 69, 52-62. doi: 10.1107/S0907444912042175

Xu, G., Searle, L. L., Hughes, T. V., Beck, A. K., Connolly, P. J., Abad, M. C., et al. (2008). Discovery of novel 4-amino-6-arylaminopyrimidine-5-carbaldehyde oximes as dual inhibitors of EGFR and ErbB-2 protein tyrosine kinases. Bioorg. Med. Chem. Lett. 18, 3495-3499. doi: 10.1016/j.bmcl.2008.05.024

Yáñez-Mó, M., Barreiro, O., Gordon-Alonso, M., Sala-Valdés, M., and Sánchez-Madrid, F. (2009). Tetraspanin-enriched microdomains: a functional unit in cell plasma membranes. Trends Cell Biol. 19, 434-446. doi: 10.1016/j.tcb.2009.06.004

Yuan, C., Furlong, J., Burgos, P., and Johnston, L. J. (2002). The size of lipid rafts: an atomic force microscopy study of ganglioside GM1 domains in sphingomyelin/DOPC/cholesterol membranes. Biophys. J. 82, 2526-2535. doi: 10.1016/S0006-3495(02)75596-3

Zalepa-King, L., and Citovsky, V. (2013). A plasmodesmal glycosyltransferase-like protein. PLoS ONE 8:e58025. doi: 10.1371/journal.pone.0058025

Zavaliev, R., Ueki, S., Epel, B., and Citovsky, V. (2011). Biology of callose ( $\beta$-1,3-glucan) turnover at plasmodesmata. Protoplasma 248, 117-130. doi: 10.1007/s00709-010-0247-0

Conflict of Interest Statement: The authors declare that the research was conducted in the absence of any commercial or financial relationships that could be construed as a potential conflict of interest.

Received: 08 December 2013; accepted: 11 May 2014; published online: 30 May 2014. Citation: Naulin PA, Alveal NA and Barrera NP (2014) Toward atomic force microscopy and mass spectrometry to visualize and identify lipid rafts in plasmodesmata. Front. Plant Sci. 5:234. doi: 10.3389/fpls.2014.00234

This article was submitted to Plant Cell Biology, a section of the journal Frontiers in Plant Science.

Copyright (c) 2014 Naulin, Alveal and Barrera. This is an open-access article distributed under the terms of the Creative Commons Attribution License (CC BY). The use, distribution or reproduction in other forums is permitted, provided the original author(s) or licensor are credited and that the original publication in this journal is cited, in accordance with accepted academic practice. No use, distribution or reproduction is permitted which does not comply with these terms. 